DOI: $10.21802 / \operatorname{artm} .2019 .4 .12 .31$.

УДК 616.12-008.331-06

\title{
ОСОБЛИВОСТІ АВТОНОМНОЇ РЕГУЛЯЦІї У МОЛОДИХ ОСІБ ІЗ РІЗНИМ РІВНЕМ АРТЕРІАЛЬНОГО ТИСКУ
}

\author{
С.Н. Вадзюк, П.С. Табас, Л.Б. Лозіна
}

Тернопільський начіональний медичний університет ім. І. Я. Горбачевського МОЗ Украӥни, кафедра фізіології з основами біоетики та біобезпеки, м. Тернопіль, Україна, ORCID ID:0000-0001-9105-8205,e-mail:vadzyuk@tdmu.edu.ua, ORCID ID: 0000-0003-4008-7457,e-mail:tabas@tdmu.edu.ua, e-mail: lozyna@tdmu.edu.ua

Резюме. Мета дослідження - дослідити особливості автономної регуляції в осіб віком 18-22 роки з різним рівнем артеріального тиску (АТ).

Матеріали та методи. У дослідженні брало участь 40 обстежуваних віком 18-22 роки з нормальним індексом маси тіла, без виявлених хронічних захворювань та шкідливих звичок. Усім обстежуваним проводили пробу Руф’є з навантаженням у вигляді 30 присідань за 2 хвилини. Вимірювання АТ виконували до та після фізичного навантаження за методом Короткова. Проводили кардіоритмографію до та після фізичного навантаження. Аналіз варіабельності серцевого ритму проводили за методом Баєвського. Статистичний аналіз проводили за методом Мана-Уітні, за допомогою програмного забезпечення Microsoft Excel тa Statistica 10.

Результати. Середньо-динамічний тиск у обстежуваних з систолічним артеріальним тиском $(\mathrm{CAT}) \leq$ 119 мм. рт. ст. після навантаження достовірно менший від рівня цього показника в обстежуваних з інших груп. Результати проби Руф'є свідчать про вищий рівень функціональних резервів в обстежуваних з САТ $\leq 119$ мм. рт. ст. Проведений аналіз варіабельності серцевого ритму виявив гіршу адаптацію регуляторних систем до фізичного навантаження у осіб з САТ $>130$ мм. рт ст.

Висновки. Встановлено вищий тонус симпатичних автономних впливів у осіб з вищим рівнем АТ. На підставі проби Руф'є виявлено вищий рівень функціональних резервів у обстежуваних з САТ $\leq 119$ мм. рт. ст. Підтверджено нижчі адаптивні можливості автономної регуляції до фізичного навантаження в осіб з САТ $\geq 130$ мм. рт. ст. на основі вищих показників TP та SDNN у них. При аналізі кардіоритмограм не виявлено достовірного зменшення рівнів та LF та HF в обстежуваних з CAT $\geq 130$ мм. рт. ст. внаслідок неадекватної відповіді симпатичного та парасимпатичного відділів автономної нервової системи на фізичне навантаження.

Ключові слова: артеріальний тиск, артеріальна гіпертензія, автономна регуляція.

Вступ. Адаптація до комплексу нових факторів, що впливають на організм, є складним багаторівневим соціально-психофізіологічним процесом та супроводжується значним напруженням компенсаторно-пристосувальних механізмів, що провокує високий ризик порушення здоров'я. Стан, при якому організм не здатний адекватно реагувати на стрес та вплив нових факторів зовнішнього середовища, описується терміном «дезадаптація» [1]. Такий стан характерний для молодих людей у період значних фізичних та психологічних навантажень. Розлади адаптації приводять серед іншого до розвитку захворювань серцево-судинної системи, чільне місце серед яких посідає артеріальна гіпертензія.

Стан автономної нервової системи є одним 3 факторів прогнозу перебігу різноманітних захворювань [2-4]. Доведеними є зміни автономної регуляції у хворих 3 діагностованою гіпертонічною хворобою. Окрім того, посилення зрушень в автономній регуляції спостерігається у пацієнтів з гіпертонічною хворобою в поєднанні із різними коморбідностями $[5,6]$. Характерними змінами, які виявляються у хворих на артеріальну гіпертензію, є надмірна активація симпатичних центрів та відносне зменшення парасимпатичних впливів.
Ефективним способом оцінки автономної регуляції функцій організму, зокрема серцево-судинної системи, є реєстрація кардіоінтервалограми 3 подальшим аналізом варіабельності серцевого ритму (BCP) [7-10].

Питання щодо нормального рівня артеріального тиску (АТ) все частіше постає серед науковців та практичних лікарів. У нещодавньому дослідженні "Systolic Blood Pressure Intervention Trial" (SPRINT) встановлено, що при лікуванні артеріальної гіпертензії (АГ) у пацієнтів 3 цільовим рівнем систолічного АТ $<120$ мм. рт. ст. виживання протягом 10 років достовірно вище ніж у пацієнтів 3 цільовим рівнем систолічного АТ < 140 мм. рт. ст. [11]. Наступним кроком у перегляді норм АТ стало прийняття Американською колегією кардіологів нових рекомендацій щодо терапії високого АТ у дорослих [12], де цільовим рівнем систолічного АТ встановлено 130/80 мм. рт. ст. У дослідженні Adi Leiba та ін. встановлено, що АГ у підлітків та молодих дорослих схильна до прогресування 3 подальшим ураженням органів-мішеней, зокрема з розвитком ниркової недостатності [13].

Обгрунтування дослідження. Питання щодо порогових рівнів артеріального тиску на даний час викликає жваві дискусії. Багато уваги приділяється 
вивченню граничних рівнів АТ у осіб старшого віку. Для пацієнтів старших 75 років доведена необхідність підтримки цільового рівня систолічного АТ менше 120 мм. рт. ст. [14]. Незважаючи на інтенсивні дослідження різних підходів у терапії гіпертонічної хвороби, недостатньо вивченим залишається питання порогових рівнів АТ у молодих осіб. Для раннього виявлення схильності до артеріальної гіпертензії та попередження розвитку гіпертонічної хвороби важливим $є$ вивчення фізіологічного підгрунтя граничного рівня АТ. Сформувати фізіологічні засади для вибору порогових норм АТ можна на підставі вивчення особливостей автономної регуляції у осіб 3 різним рівнем АТ.

Мета дослідження. Дослідити особливості автономної регуляції в осіб віком $18-22$ роки 3 різним рівнем артеріального тиску.

Матеріали та методи. Дослідження проводили на базі атестованої MO3 України лабораторії психофізіологічних досліджень кафедри фізіології 3 основами біоетики та біобезпеки Тернопільського національного медичного університету імені І. Я. Горбачевського МО3 України (Свідоцтво № 055/13). $\mathrm{У}$ ході роботи дотримувались біоетичних норм Гельсінської декларації Всесвітньої медичної асоціації «Етичні принципи медичних досліджень за участю людини у якості об'єкта дослідження» (прийнята 59ою Генеральною асамблеєю, перегляд від жовтня 2008 року), Міжнародного кодексу медичної етики та законів України (рішення комісії з біоетики ДВНЗ «Тернопільський державний медичний університет імені І.Я. Горбачевського МОЗ України», протокол № 54 від 27 серпня 2019 р.)

У дослідженні брало участь 40 обстежуваних віком 18-22 роки з нормальним індексом маси тіла, без виявлених хронічних захворювань та шкідливих звичок. Усім обстежуваним проводили пробу Руф'є [15-17] з навантаженням у вигляді 30 присідань за 2 хвилини. Вимірювання АТ виконували до та після фізичного навантаження за методом Короткова. Проводили кардіоритмографію до та після фізичного навантаження. Аналіз варіабельності серцевого ритму проводили за методом Баєвського $[18,19]$. Статистичний аналіз проводили за методом Мана-Уітні, за допомогою програмного забезпечення Microsoft Excel та Statistica 10.

Результати дослідження. Усіх обстежуваних було поділено на 3 групи відповідно до їх артеріального тиску у спокої. До І групи віднесли осіб з систолічним АТ $\leq 119$ мм. рт. ст., до II групи - 120129 мм. рт. ст., та до III групи $\geq 130$ мм. рт. ст.

Середньо-динамічний тиск до навантаження у обстежуваних з I групи становив 85,0 \pm 4,27 мм. рт. ст., після навантаження - 101,25 $\pm 5,89$ мм. рт. ст., у обстежуваних 3 II групи до навантаження 93,19 $\pm 3,13$ мм. рт. ст., після навантаження $106,25 \pm 3,42$ мм. рт. ст., а у обстежуваних з III групи до навантаження - $100,77 \pm 4,45$ мм. рт. ст., після навантаження - 107,51土 6,57 мм. рт. ст. Достовірно встановлено (p< $<0,05)$ зростання середньодинамічного тиску після навантаження в осіб II та III груп.
У обстежуваних з І групи індекс Руф’є склав $7,0 \pm 0,828$, що відповідає доброму функціональному стану серцево-судинної системи. У обстежуваних з II групи індекс Руф'є склав 9,8 $\pm 1,072$, що відповідає задовільному функціональному стану. У обстежуваних 3 III групи індекс Руф'є склав 10,16 0,879, що також відповідає задовільному функціональному стану. Встановлено достовірну різницю $(\mathrm{p}<0,05)$ індексу Руф'є між обстежуваними з І групи та в обстежуваних 3 II групи, а також між обстежуваними 3 I групи та в обстежуваних з III групи. При цьому між значеннями індексу Руф’є в осіб з II групи та III групи достовірної різниці не виявлено.

Показник ТР (сумарна площа варіабельності серцевого ритму в $\mathrm{cm}^{2}$ ) до навантаження склав у осіб I групи 7914,125 \pm 163.42 , після навантаження $1959,0 \pm 117,37$, у осіб II групи до навантаження $3920.92 \pm 143,37$, після навантаження $2664,417 \pm 135,180$, та у осіб III групи до навантаження - $6291,73 \pm 114,38$, після навантаження $4251,6 \pm 167,824$. Встановлено, що існує достовірна різниця $(\mathrm{p}<0,05)$ показника ТР після фізичного навантаження між особами з I групи та III групи, а також між особами 3 II групи та III групи, однак у спокої достовірної різниці показника ТР між різними групами не було виявлено.

Показник SDNN (стандартне відхилення повного масиву кардіоінтервалів) до фізичного навантаження становив у обстежуваних з І групи 74,38 $\pm 2,8$, після навантаження - 38,125 $\pm 2,78$, у обстежуваних 3

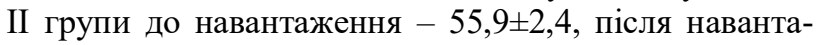
ження - 44,5 7,3 , та у обстежуваних з III групи до навантаження - 72,7 $\pm 3,1$, після навантаження $59,8 \pm 4,8$. Виявлено достовірну різницю ( $<<0,05)$ показника SSNN після навантаження між обстежуваними 3 I та III групи та між обстежуваними з II та III групи. У стані спокою достовірної різниці показника SDNN між різними групами не було встановлено.

Показник VLF (хвилі дуже низької частоти) у обстежуваних 3 I групи до фізичного навантаження становив $3958,625 \pm 104,85$, після навантаження $805,75 \pm 35,46$. Встановлено достовірну різницю ( $<<$ $0,05)$ між рівнем VLF у I групі до навантаження та після навантаження. У обстежуваних 3 II групи до навантаження VLF становив $1427,75 \pm 56,03$, після навантаження - 1075,58 $\pm 75,8$. У II групі встановлено достовірну різницю $(\mathrm{p}<0,05)$ між рівнем VLF до навантаження та після навантаження. В обстежуваних 3 III групи рівень VLF до навантаження склав $2377,0 \pm 105,57$, після навантаження $-1383,6 \pm 86,95$. У III групі виявлено достовірну різницю $(\mathrm{p}<0,05)$ між рівнем VLF до навантаження та після навантаження.

Показник LF (хвилі низької частоти) у осіб з I групи до фізичного навантаження становив $1743,0 \pm 27,93$, після навантаження - 554,5 $\pm 36,14$. Встановлено достовірну різницю $(\mathrm{p}<0,05)$ між рівнем LF у I групі до навантаження та після навантаження. У обстежуваних 3 II групи до навантаження LF становив $1059 \pm 64,8$, після навантаження 796,25 $\pm 24,61$. В обстежуваних з III групи рівень LF до навантаження склав - $1542,66 \pm 88,3$, після наванта-

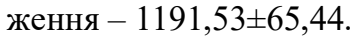


Показник HF (хвилі високої частоти) у обстежуваних 3 I групи до фізичного навантаження становив 2212,25 $\pm 115,85$, після навантаження $598,7 \pm 36,12$. Встановлено достовірну різницю (p < $0,05)$ між рівнем HF у I групі до навантаження та після навантаження. У обстежуваних 3 II групи до навантаження НF становив $1433,8 \pm 56,9$, після навантаження - 792,75 $\pm 18,51$. У II групі встановлено достовірну різницю $(\mathrm{p}<0,05)$ між рівнем НF до навантаження та після навантаження. В обстежуваних з III групи рівень НF до навантаження склав $2372,26,0 \pm 113,58$, після навантаження - 1676,53 $\pm 52,8$.

Обговорення результатів. Середньодинамічний тиск у обстежуваних 3 I групи після навантаження достовірно відрізняється від рівня цього показника в обстежуваних II та III груп. Отримані дані свідчать про більші резерви серцево-судинної системи в обстежуваних з I групи. Одним із загально прийнятих критеріїв функціонального стану серцевосудинної системи є проба Руф’є $[16,17]$. Ї̈ результати також свідчать на користь гіпотези про вищий рівень функціональних резервів в обстежуваних 3 I групи, оскільки виявлено достовірну різницю між обстежуваними з I групи та обстежуваними з II і III груп.

Проведений аналіз варіабельності серцевого ритму встановив, що показник ТР (сумарна площа варіабельності серцевого ритму в $\mathrm{cm}^{2}$ ), що показує сумарний абсолютний рівень активності регуляційних систем після навантаження, достовірно вищий у обстежуваних із III групи порівняно із обстежуваними 3 I та II груп. Такі результати свідчать про гіршу адаптацію регуляторних систем до фізичного навантаження у осіб III групи. Показник SDNN (стандартне відхилення повного масиву кардіоінтервалів) також достовірно вищий у обстежуваних із III групи порівняно із обстежуваними з I та II груп, що пояснюється збільшеним сумарним ефектом автономної регуляції кровообігу, як наслідок гіршого пристосування до фізичного навантаження в обстежуваних 3 III групи. Нами виявлено достовірне зменшення після фізичного навантаження показників VLF (хвилі дуже низької частоти), LF (хвилі низької частоти) та HF (хвилі високої частоти) у обстежуваних 3 I групи, що свідчить про нормальну реакцію на фізичне навантаження всіх відділів автономної нервової системи. У обстежуваних 3 II групи після фізичного навантаження достовірно зменшувались показники VLF та HF (хвилі високої частоти), що пояснюється адекватною реакцією на фізичне навантаження з боку парасимпатичної системи та гормональних впливів. У осіб з III групи у відповідь на фізичне навантаження достовірно зменшився лише показник VLF (хвилі дуже низької частоти). Отримані результати є наслідком неадекватної відповіді симпатичного та парасимпатичного відділів автономної нервової системи на фізичне навантаження.

Висновки. Встановлено достовірну різницю середньо-динамічного тиску після фізичного навантаження між особами з систолічним АТ $\leq 119$ мм. рт. ст. та особами $з$ систолічним АТ 120-129 мм. рт. ст., та між особами з систолічним АТ $\leq 119$ мм. рт. ст. та особами з систолічним АТ $\geq 130$ мм. рт. ст., що свід- чить про вищий тонус симпатичних автономних впливів в осіб з вищим рівнем АТ. На підставі проби Руф'є виявлено вищий рівень функціональних резервів в обстежуваних з систолічним АТ $\leq 119$ мм. рт. ст. Підтверджено нижчі адаптивні можливості автономної регуляції до фізичного навантаження у осіб 3 систолічним АТ $\geq 130$ мм. рт. ст. на основі вищих показників TP та SDNN у них. При аналізі кардіоритмограм не виявлено достовірного зменшення рівнів та LF та HF в обстежуваних з систолічним AT $\geq 130$ мм. рт. ст. внаслідок неадекватної відповіді симпатичного та парасимпатичного відділів автономної нервової системи на фізичне навантаження.

\section{References:}

1. Isayeva IN. Adaptatsiyni reaktsiyi sertsevo-sudynnoyi systemy $\mathrm{V}$ osib molodoho viku $\mathrm{Z}$ arterial'noyu hipotenziyeyu [Adaptation reactions of the cardiovascular system in young people with arterial hypotension]. 2016. 2. Seredyuk NM, Galyuk NM, Nauzhnaya TV, Yusynchuk UV. Osoblyvosti variabelnosti sertsevoho rytmu u khvorykh na neyrotsyrkulyatornu dystoniyu. [Peculiarities of heart rate variability in patients with neurocirculatory dystonia] Arkhiv klinichnoyi medytsyny. 2013; (1(19)):79-81.

3. Horsha OV, Korolenko NV, Mykhaylenko VE. Variabel'nist sertsevoho rytmu $\mathrm{v}$ ditey iz tservikohennym holovnym bolem [Heart rate variability in children with cervicogenic headache]. Aktualni Pytannya Pediatriyi, Akusherstva Ta Hinekolohiyi . 2016; (2):9-11.

4. Indyka S, Yahenskyy A, Dukhnevych L. Variabelnist sertsevoho rytmu u khvorykh pislya infarktu miokarda na ambulatornomu etapi reabilitatsiyi [Variability of cardiac rhythm in patients after myocardial infarction at the outpatient rehabilitation stage]. Moloda Sportyvna Nauka Ukrayiny. 2011; 3:136-42.

5. Kitayeva YEA, Tuyev AV, Khlynova OV. Variabelnost ritma serdtsa $\mathrm{u}$ patsiyentov $\mathrm{s}$ arterialnoy gipertenziyey $\mathrm{v}$ sochetanii $\mathrm{s}$ kislotozavisimymi zabolevaniyami. Permskiy meditsinskiy zhurnal [Heart rate variability in patients with arterial hypertension in combination with acid-dependent diseases]. 2010; 27(5):26-32.

6. Tomina OYE, Bychkova OYU, Fomych HM, Ivleva OO, Okhryamkina OO, Usan' NYU. Variabel'nist' sertsevoho rytmu $u$ khvorykh na komorbidnu $\mathrm{z}$ vyrazkovoyu khvoroboyu arterial'nu hipertenziyu, z urakhuvannyam dobovykh profiliv systolichnoho arterial'noho tysku [Heart rate variability in patients with comorbid peptic ulcer arterial hypertension, taking into account the daily profiles of systolic blood pressure]. Visnyk KHNU imeni V N Karazina. 2012; 1024:52-62.

7. Ban AS. Metodologicheskiye aspekty provedeniya i analiza variabel'nosti ritma serdtsa [Methodological aspects of conducting and analyzing heart rate variability.]. 2001. P.145.

8. Mikhaylov VM. Variabelnost ritma serdtsa opyt prakticheskogo primeneniya [Heart rate variability practical experience]. 2000. P.183.

9. Kovalenko S, Kudiy L. Variabel'nist Sertsevoho Rytmu. Metodychni Aspekty [Heart Rate Variability. Methodical Aspects]. 2016. P.298. 
10. Kovalenko SO. Analiz variabelnosti sertsevoho rytmu za dopomohoyu metodu mediannoyi spektrohramy [Analysis of heart rate variability using the median spectrogram method]. Fiziolohichnyy zhurnal. 2005; 51(3):92-5.

11. Cushman WC, Whelton PK, Fine LJ, Wright JT, Reboussin DM, Johnson KC, et al. SPRINT Trial Results: Latest News in Hypertension Management. Hypertension. 2016; 67(2):263-5.

12. Whelton PK, Carey RM, Aronow WS, Ovbiagele B, Casey DE, Smith SC, et al. 2017 ACC/AHA/AAPA/ABC/ACPM/AGS/APhA/ASH/ASPC /NMA/PCNA Guideline for the Prevention, Detection, Evaluation, and Management of High Blood Pressure in Adults [Internet]. Journal of American College of Cardiology. 2017. P.283. Available from: http://www.ncbi.nlm.nih.gov/pubmed/29133356

13. Leiba A, Twig G, Vivante A, Skorecki K, Golan E, Derazne E, et al. Prehypertension among 2.19 million adolescents and future risk for end-stage renal disease. $\mathrm{J}$ Hypertens. 2017; 35(6):1290-6.

14. Williamson JD, Supiano MA, Applegate WB, Berlowitz DR, Campbell RC, Chertow GM, et al. Intensive vs standard blood pressure control and cardiovascular disease outcomes in adults aged $\geq 75$ years a randomized clinical trial. JAMA - J Am Med Assoc. 2016; 315(24):2673-82.

15. Babanin AO. Doslidzhennya metodiv vyznachennya funktsionalnoho stanu sport·smena ta yikh vprovadzhennya u kompyuternu systemu upravlinnya trenuval'nym protsesom [Investigation of the methods of determining the functional state of the athlete and their introduction into the computer control system of the training process]. 2006; 7(26):5-8.

16. Zanevskyy IP, Zanevska LH. Model proby rufye z urakhuvannyam viku patsiyenta. Teoriya Ta Metodyka Fizychnoho Vykhovannya [The Ruffier test model is tailored to the patient's age]. 2013;2:17.

17. Melnychuk LV, Bandura SM. Rezul'taty vprovadzhennya proby Rufye pid chas profilaktychnykh ohlyadiv shkolyariv mista Chernivtsi [Results of the implementation of the Ruffier test during the preventive examinations of Chernivtsi students]. Semeynaya medytsyna. 2016; 2(64):138-40.

18. Bayevskiy RM. Analiz variabelnosti serdechnogo ritma [Heart rate variability analysis]. Klinicheskaya informatika i Telemeditsina. 2004;(1).

19. Bayevskiy RM, Ivanov GG, Chireykin LV, Gavrilushkin AP, Dovgalevskiy PYA. Analiz variabel'nosti serdtsechnogo ritma pri ispolzovaniya razlichnykh elektrokadiograficheskikh sistem [Analysis of heart rate variability using various electrocardiographic systems]. Vestnik aritmologii. 2001; (24):65-87.
УДК 616.12-008.331-06

\section{ОСОБЕННОСТИ АВТОНОМНОЙ РЕГУЛЯЦИИ У МОЛОДЫХ ЛИЦ С РАЗНЫМ УРОВНЕМ АР- ТЕРИАЛЬНОГО ДАВЛЕНИЯ}

\author{
С.Н. Вадзюк, П.С. Табас, Л.Б. Лозина
}

Тернопольский национальный медицинский университет им. И. Я. Горбачевского МОЗ Украины, кафедра физиологии с основами биоэтики и биобезопасности, 2. Тернополь, Украина,

ORCID ID: 0000-0001-9105-8205,

e-mail:vadzyuk@tdmu.edu.ua,

ORCID ID: 0000-0003-4008-7457,

e-mail:tabas@tdmu.edu.ua,

e-mail: lozyna@tdmu.edu.ua

Резюме. Цель исследования - исследовать особенности автономной регуляции у лиц в возрасте 18-22 года с разным уровнем артериального давления (АД).

Материалы и методы. В исследовании участвовало 40 обследуемых в возрасте 18-22 года с нормальным индексом массы тела, без выявленных хронических заболеваний и вредных привычек. Всем обследуемым проводили пробу Руфье с нагрузкой в виде 30 приседаний за 2 минуты. Измерение АД выполняли до и после физической нагрузки по методу Короткова. Проводили кардиоритмографию до и после физической нагрузки. Анализ вариабельности сердечного ритма проводили по методу Баевского. Статистический анализ проводили по методу МанаУитни, с помощью программного обеспечения Microsoft Excel и Statistica 10.

Результаты. Средне-динамическое давление в обследуемых с систолическим артериальным давлением $($ САД $) \leq 119$ мм. рт. ст. после нагрузки достоверно меньше уровня этого показателя у обследуемых из других групп. Результаты пробы Руфье свидетельствуют о более высоком уровне функциональных резервов у обследуемых с САД $\leq 119$ мм. рт. ст. Проведенный анализ вариабельности сердечного ритма обнаружил худшую адаптацию регуляторных систем к физической нагрузке у лиц с САД > 130 мм. рт ст.

Выводы. Установлено более высокий тонус симпатических автономных воздействий у лиц с высоким уровнем АД. На основании пробы Руфье выявлено более высокий уровень функциональных резервов у обследуемых с САД $\leq 119$ мм. рт. ст. Подтверждено ниже адаптивные возможности автономной регуляции к физической нагрузке у лиц с САД $\geq 130$ мм. рт. ст. на основе высоких показателей TP и SDNN в них. При анализе кардиоритмограм не обнаружено достоверного уменьшения уровней и LF и HF в обследуемых с САД $\geq 130$ мм. рт. ст. вследствие неадекватного ответа симпатичного и парасимпатического отделов автономной нервной системы на физическую нагрузку.

Ключевые слова: артериальное давление, артериальная гипертензия, автономная регуляция. 
UDC 616.12-008.331-06

FEATURES OF AUTONOMOUS REGULATION IN YOUNG PEOPLE WITH DIFFERENT LEVEL OF ARTERIAL BLOOD PRESSURE

\section{S.N. Vadiuk, P.S. Tabas, L.B. Lozina}

Ternopil National Medical University Gorbachevsky IH of Ukraine, Department of Physiology with Fundamentals of Bioethics and Biosafety, Ternopil, Ukraine,

ORCID ID: 0000-0001-9105-8205,

e-mail:vadzyuk@tdmu.edu.ua,

ORCID ID: 0000-0003-4008-7457,

e-mail:tabas@tdmu.edu.ua,

e-mail: lozyna@tdmu.edu.ua

Abstract. The purpose of the study is to investigate features of autonomous regulation in persons aged 18-22 years with different levels of blood pressure (BP).

Materials and methods. The study involved 40 people aged 18-22 years with a normal body mass index, with no identified chronic illnesses or bad habits. All people were run a 30-squat Ruffier test in 2 minutes. Measurements of blood pressure were performed before and after physical activity by the Korotkov method. Cardiac rhythmography was performed before and after exercise. Analysis of heart rate variability was performed using Bayevsky method. Statistical analysis was performed using Mann-Whitney u-test, using Microsoft Excel and Statistica 10 software.

Results. The average dynamic pressure in subjects with systolic blood pressure(SBP) is $\leq 119$ $\mathrm{mmHg}$ after physical activity significantly less than the level of this indicator in the subjects from other groups. The results of Ruffier test indicate a higher level of functional reserves in the surveyed with $\mathrm{SBP} \leq 119$ $\mathrm{mmHg}$. The analysis of heart rate variability revealed the poorer adaptation of regulatory systems to exercise of individuals with $\mathrm{SBP}>130 \mathrm{mmHg}$.

Discussion. The data obtained indicate a greater reserve of the cardiovascular system in the subjects from group I. The conducted analysis of heart rate variability found that TP (total area of heart rate variability in $\mathrm{cm}^{2}$ ), which shows the total absolute level of activity of the control systems after physical activity, is significantly higher in the subjects from group III compared to those from groups I and II. Such results indicate a worse adaptation to physical activity in group III individuals. The SDNN (standard deviation of the full array of cardio intervals) is also significantly higher in the subjects of group III. We found a significant decrease after exercise of VLF (very low frequency), LF (low frequency) and HF (high frequency) indices in subjects from group I, which indicates a normal reaction to physical activity of all parts of the autonomic nervous system. The subjects of group II after exercise significantly decreased the VLF and HF, which is explained by the adequate response to physical activity from the parasympathetic system and hormonal influences. In group III individuals, only VLF decreased significantly in response to physical activity. The results are a consequence of inadequate response of the sympathetic part of the autonomic nervous system to exercise.

Conclusions. A significant difference in mean dynamic pressure after physical exertion was established between individuals with systolic blood pressure $\leq 119$ $\mathrm{mmHg}$. and persons with systolic blood pressure of 120 $129 \mathrm{mmHg}$ and between persons with systolic blood pressure $\leq 119 \mathrm{mmHg}$ and individuals with systolic blood pressure $\geq 130 \mathrm{mmHg}$ that indicates a higher tone of sympathetic autonomic influences in individuals with higher levels of blood pressure. On the basis of the Rufier sample, a higher level of functional reserves was found in the examined with systolic blood pressure $\leq 119 \mathrm{mmHg}$. Lower adaptive possibilities of autonomous regulation to physical activity in persons with systolic blood pressure $\geq$ $130 \mathrm{mmHg}$ have been confirmed. based on higher TP and SDNN scores in them. In analysis of cardiorhythmograms, no significant decrease in levels of both LF and HF was observed in the subjects with systolic blood pressure $\geq 130 \mathrm{mmHg}$ as a result of inadequate response of the sympathetic and parasympathetic parts of the autonomic nervous system to exercise.

Keywords: blood pressure, hypertension, autonomic regulation. 